\title{
Roll Over Beethoven - sähkökitaramusiikin uudet kasvot
}

Sähkökitaraan liittyvä tutkimus Suomessa on ollut melko vähäistä. Pro Gradu -töitä on tehty kaksi: Björn Eklundin "Bluesfraset hos Eric Clapton" vuodelta 1987 ja Ismo Savolan "Jimi Hendrixin maailmankuva ja musiikki käsitteistö" vuodelta 1989. Ismo Savola on tehnyt myös lisensiaattityön aiheesta "Jimi Hendrixin improvisointitekniikka" vuonna 1991.

Nämä opinnäytteet kattavat kyllä 1960- ja 1970-luvun vaihteessa vaikuttaneiden legendojen musiikin hyvinkin laajamerkityksellisellä tasolla. Sähkökitaran alueella on kuitenkin tapahtunut 1970-luvun jälkeen paljon sellaista, joka on tutkimisen arvoista. Tämä artikkeli käsittelee erästä 1980-luvun sähkökitaramusiikkissa noussutta ilmiötä, neoklassismia.

\section{Neoklassismi}

Tässä artikkelissa käyttämäni termi viittaa siihen ilmiöön, josta alettiin yleisesti käyttää nimitystä neoklassismi. Eri asia kuitenkin on, voidaanko musiikin tutkimuksessa puhua erillisestä, aikaisemmasta poikkeavasta tyylilajista. Uuden termin käyttöönotto on useimmiten oire jostain muutoksesta, jota vanhat määritelmät eivät riitä enää kuvaamaan. 
Klassisen musiikin ainesten käyttö rock-musiikissa ei sinänsä ole mitään uutta. Esimerkiksi Deep Purple -yhtyeen "Highway Star" kappaleen (Machine Head, 1972) väliosa sisältää paljon sävelkuvioita, joita käytetään klassisessa musiikissa. Tässä ei kuitenkaan ole kyse mistään uudesta tyylistä. Musiikissa käytetään ainostaan tilapäisesti joko suoria sitaatteja tai alluusioita, joilla ei ole sen suurempaa kokonaisuuteen vaikuttavaa merkitystä.

Historiallinen tosiasia on tietenkin se, että näistä ilmiöistä rockmusiikin keskuudessa on käytetty termiä klassisvaikutteinen rock. Tämä ei kuitenkaan poista sitä mahdollisuutta, etteikö musiikin tutkimus voisi määritellä kyseistä ilmiötä toisella tavalla. Jos vaikutteet ovat lähinnä marginaalisia, on kyseenalaista käyttää ylipäätänsä koko termiä.

Termi, neoklassismi, tarkoittaa tämän artikkelin yhteydessä musiikillista kokonaisuutta. Tämä musiikillinen kokonaisuus koostuu tekijöistä, joiden vaikutteet ovat peräisin klassisesta musiikista. Neoklassismissa melodiset ja harmoniset ideat pohjautuvat barokin ajan sävellystyyliin, suurena esikuvana J.S.Bach. Itse soittotapahtumaan voidaan liittää käsite, virtuositeetti, joka viittaa taidemusiikissa 1800 luvun jälkipuoliskon ilmiöön, esikuvina N.Paganini ja F.Chopin.

\section{Alussa}

Guitar Player -lehden kolumnisti, Mike Varney, on neoklassisuuden kannalta erittäin tärkeä henkilö. Varneyn pitämä palsta, "Spotlight", on eräänlainen uusien kykyjen foorumi, jossa esitellään demonauhan perusteella mielenkiintoisimmat ja kehityskelpoisimmat äänitteet. Artikkelissa esitellään kitaristit ja kuvaillaan lyhyesti heidän musiikkiaan ja soittoaan.

Vuoden 1983 helmikuun numerossa esiteltiin ruotsalainen kitaristi, Yngvie J. Malmsteen, joka on tehnyt ensimmäisen neoklassismia edustavan levyn, "Rising Force", vuonna 1984. Tätä ennen Malmsteen oli lyhyen ajan Alcatrazz-yhtyeessä, jossa oli laulajana Rainbow-yhtyeestä tuttu Graham Bonnet. Tämä kokoonpano ehti tehdä yhden studiolevyn, minkä jälkeen Malmsteen kokosi oman yhtyeensä Yngvie J. Malmsteen's Rising Force. (Obrecht 1985, 60).

Yngvie J. Malmsteenin lisäksi kyseisen lehden numerossa kerrotaan 15-vuotiaasta Paul Gilbert -nimisestä kitaristista, joka on harjoitellut Vivaldin "Neljä vuodenaikaa" sähkökitaralla. Gilbert on tullut tun- 
netuksi myöhemmin Racer X- ja Mr.Big- yhtyeiden kautta. Hän on myös nykyään kolumnistina Guitar Player -lehdessä. (Varney 1983, 142).

Vaikka Yngvie J. Malmsteen oli ensimmäinen neoklassismin edustaja, oli samanaikaisesti myös muita kitaristeja, jotka olivat tehneet samantyylistä musiikkia. Jo tammikuussa 1985 esiteltiin jälleen "Spotlight"-artikkelissa uusi tulokas, Vinnie Moore. Mike Varney toteaa Mooresta seuraavaa:

"Not since spotlighting Yngvie Malmsteen in the Feb. '83 issue have I been so impressed by a new talent in the heavy metal genre." (Varney 1985, 96).

Visious Rumours -yhtyeen ja kansainvälisen Pepsi Cola -mainoksen jälkeen Vinnie Moore teki ensimmäisen soololevyn, "Mind's Eye", vuonna 1987, jonka tuottajana oli Mike Varney. (Obrecht 1987, 10).

Elokuussa 1985 "Spotlight"-artikkelissa esitellään kitaristi, Tony MacAlpine, joka poikkeaa aikaisemmin mainituista henkilöistä. MacAlpine opiskeli pianon soittoa Springfieldin konservatoriossa Marion Jensenin johdolla 12 vuotta. Hänen konserttiohjelmistossaan oli monia keskeisiä pianoteoksia, kuten Beethovenin pianosonaatit, Chopinin etydit ja preludit, Listzin h-mollisonaatti ja Saint-Seansin pianokonsertto nro 1, g-molli. (Obrecht 1986, 16).

Tony MacAlpine teki ensimmäisen soololevyn, "Edge Of Insanity", vuonna 1986. Tuottajana oli jälleen kerran Mike Varney. ${ }^{1}$

\section{Next}

Metal Hamer -lehden toimittaja Oliver Klemm kritisoi vuoden 1988 heinäkuun numerossa Mike Varneya levyjen ylituotannosta ja ylipäätänsä vääränlaisen "kitarasankarin" muotin luomisesta. Hän kirjoittaa artikkelissaan seuraavaa:

"There are those, with some justification, who profess to hate Mike Varney. The Californian guitar guru is responsible for a partilarly gruesome kind of torture! He keeps discovering socalled guitar heroes and unleashing them on an unsuspecting public who ages ago gave up trying to tell the difference between Marty Friedmann finger strings and Joey Taffola 
striking chords, or Jason Baker fumbling with his guitar neck! - God knows how many instrumental albums recorded by one oh the new Varney idols. You just put the record aside with all the others, you wish you had never bought and quite right too! (Klemm 1988, 75).

Artikkelissaan Oliver Klemm haastattelee Vinnie Moorea, joka myös kritisoi Mike Varneya ja hänen levytuotantoaan Mooren ensimmäisen soololevyn aikana:

"I can't agree with that as far as my songwriting and my guitar playing goes. The production was mainly to blame. I didn't do the compositions justice. It was the typical Varney sound and I wasn't at all happy with it. In comparison to all the new Mike Varney axemen who not only sound the same but play the same, I'm sure I've found my own style." (Ibid.)

\section{Neoklassismin ominaispiirteitä}

1. Neoklassinen musiikki on eräs heavyrockin alalaji (Obrecht 1985, 60). Itse termi ei kuitenkaan ole vakiintunut, vaan siitä on käytetty rinnakkain useimpia ilmauksia, kuten klassisvaikutteinen musiikki (Varney 1986b, 128) tai klassinen instrumentaalirock (Varney 1986a, 138). Onpa sitä väitetty jopa uudeksi 1900 -luvun klassiseksi musiikiksi (Obrecht 1985, 62).

2. Musiikista voidaan löytää selviä sitaatteja tai alluusioita barokkimusiikista. Selkeää jakoa näiden kahden välille on kuitenkin vaikea tehdä, koska tyylikeinot olivat kaikkien säveltäjien tiedossa ja käytössä. Kyse oli vain siitä, kuka osasi käyttää niitä parhaiten. J.S.Bach oli barokin suurmestari, joka on ollut monelle neoklassikolle säveltäjäesikuva ja suuri innoittaja musiikin tekemisessä. Esimerkiksi Yngvie J. Malmsteen ja Vinnie Moore ovat tehneet omia sovituksia Bachin kappaleista. Tony MacAlpine on tehnyt oman sovituksensa F.Chopinin 3. pianosonaatin largo-osasta, opus 58.

Neoklassismin harmoniassa vallitsee selkeä duuri/molli -tonaaliteetti välidominantteineen ja harmonisine molleineen.

3. Neoklassinen musiikki on instrumentaalimusiikkia, jossa soitinkokoonpanona on useimmiten sähkökitara, basso ja rummut sekä kosketinsoittimet. Sähkökitara on solisti. Vaihtoehtoisesti kosketinsoit- 
timien tilalla saatetaan käyttää toista sähkökitaraa.

4. Tekninen taituruus on olennainen ja omasta mielestäni myöskin mielenkiintoisin osa koko neoklassismia. Eritoten nopeus on kriteeri, joka hallitsee lähes koko soittoa. Neoklassisen musiikin myötä on kiinnitetty huomiota yhä enenevässä määrin tekniikkaan ja sitä kautta myös uusiin soittoteknisiin ratkaisuihin. Tekninen taituruus ja virtuositeettikäsitteen syntyminen 1800-luvun jälkipuolella ovat esikuvallisessa mielessä vaikuttajina neoklassisessa sähkökitaramusiikissa. Ainakin tilanne neoklassismissa näyttää ihan samanlaiselta kuin se oli taidemusiikin keskuudessa noin 150 vuotta sitten.

Viuluvirtuoosi N. Paganini on suuri esikuva Yngvie J. Malmsteenille. Varsinkin Paganinin 24 kapriisia ovat olleet merkittävänä innoittajana Malmsteenin kitaransoitossa (Obrecht 1985, 59). Tony MacAlpine on puolestaan mieltynyt F.Chopinin pianomusiikkiin, joka heijastuu jo soololevyillä soitetuista Chopinin kappaleista (Preludi nro 16 , opus 28 ja etydi nro 4, opus 10).

\section{Soittoteknisiä ratkaisuja}

Tässä kappaleessa on tarkoituksena syventyä itse soittotapahtumaan nuottiesimerkkien avulla. Jokaiselle soittimelle on luonnollisesti tärkeää osata valita sujuvat sormitukset, jotta mielekäs soitto olisi ylipäätänsä mahdollista. Myös sähkökitaran soitossa aseman ja sormituksen valinnalla on erittäin suuri merkitys. Esimerkiksi $c^{1}-$ sävel voidaan soittaa kitaralla viidestä eri kohdasta.

Aseman valintaan vaikuttaa se, kuinka jokin sävelkulku etenee ja minkälainen sointiväri kyseiselle sävelelle halutaan. Sointisävyn ero on melko suuri verratessa esimerkiksi kolmannelta kieleltä otettua a:ta kuudennelta kieleltä otettuun.

\section{Asteikkosoitto}

Jo aiemmin tämän artikkelin yhteydessä on tullut esille nopeuden tärkeys. Nopeuden myötä on asteikkosoitosta tullut olennainen osa koko soittoa. Perinteisesti asteikkosoittoa on opetettu tavalla, jossa vasemman käden poikittaisliike otelaudalla on mahdollisimman pieni. 
Esimerkiksi kahden oktaavin G-duuriasteikkoa soitettaessa vasen käsi ei liiku poikittaissuunnassa lainkaan. Sormitus on seuraavanlainen:

Kuva 1.

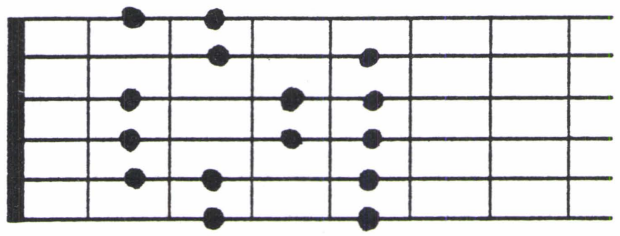

Esimerkissä sävelten määrä kielillä vaihtelee kahdesta kolmeen. Tämä käytänne on teoriassa hyvä, mutta yhä kehittyneemmän nopeuden ja tekniikan myötä se on tullut soittimellisesti epäkäytännölliseksi.

Vinnie Moore selvittää opetusvideolla, "Speed, Accuracy And Articulation", "kolme säveltä/kieli -periaatteen" käyttöä. Pääperiaate on se, että jokaisella kielellä on yhtä paljon soitettavia säveliä. Aina ei tietenkään ole mielekästä käyttää kyseistä menetelmää, vaan kuten on jo tullut esille, soitettavan kulun kokonaisuus ja soittimellisuus ratkaisevat soittotavan valinnan. "Kolme säveltä/kieli periaatteella" kahden oktaavin G-duuriasteikosta tulee seuraavanlainen:

Kuva 2.

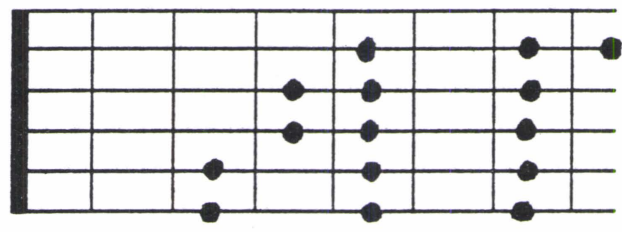

Sävelkulun muodostuessa selvästi neljän sävelen ryhmistä, voidaan edellä mainittua käytäntöä soveltaa myös tähän. Poikkeuksena on kuitenkin se, että neljän sävelen ryhmästä viimeinen soitetaan glissandona. Tällaista ratkaisua käyttää muun muassa Yngvie J. Malmsteen.

Kuva 3.

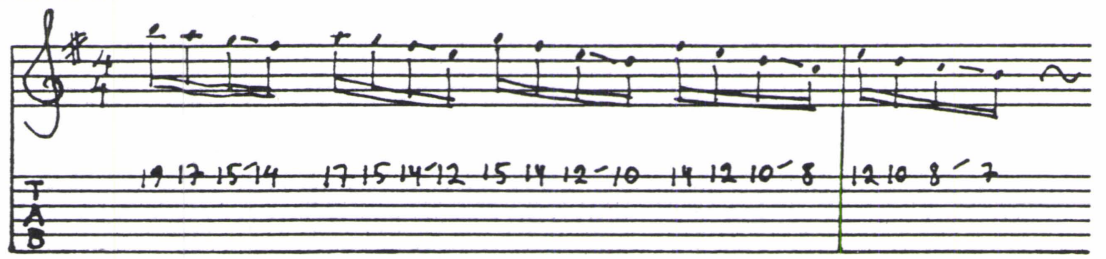




\section{Hammer-On, Pull-Off ja Tapping}

Luonteva johdannainen edellämainitusta on nopeitten Hammer-On ja Pull-Off -sarjojen käyttö, sillä se noudattaa asteikkokulkujen soittoperiaatetta. Kahden sävelen Hammer-On - ja Pull-Off -yhdistelmä on trilli, mutta kolmea säveltä käyttämällä saadaan aikaiseksi pieni sävelkulku ja näitä yhdistämällä suurempi sävelinen kokonaisuus.

Erottavana tekijänä asteikkosoitosta on se, ettei säveliä soiteta plektralla, vaan lyömällä säveliä (Hammer-On) ja päästämällä ne (Pull-Off). Kuitenkin tällaisen sarjan ensimmäinen sävel soitetaan poikkeuksellisesti plektralla tai oikean käden kolmannella tai neljännellä sormella, jotta sävelkulun alku olisi selkeästi kuultavissa.

Alla olevassa esimerkissä on Hammer-On merkitty $\mathrm{H}$-kirjaimella ja Pull-Off P-kirjaimella. Ylöspäin liikkuvat sävelkulut koostuvat Hammer-On -lyönneistä ja alaspäin menevät Pull-Off -päästöistä. Nämä kirjaimet ilmaisevat siis samalla sävelkulun suunnan.

Kuva 4.

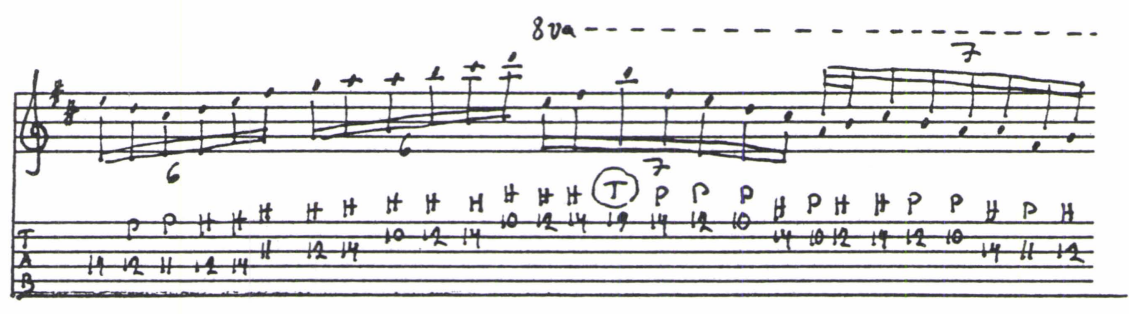

Esimerkin kolmannella tahtiosalla olevan $h^{2}$-sävelen kohdalle on merkitty kirjain T. Tämä tarkoittaa niin sanottua Tapping-tekniikkaa (naputtaa, naputus). Ensimmäiseltä kieleltä alkavan sävelkulun neljäs sävel, $h^{2}$, soitetaan "täppäämällä" oikean käden etu- tai keskisormella riippuen siitä missä plektraa pidetään. Tällä tavalla saadaan ikään kuin "lisäsormi" auttamaan tilanteeseen, joka muuten olisi mahdoton toteuttaa.

Tapping-tekniikka ei ole mikään uusi keksintö. Jo vuonna 1968 Harvey Mandel käytti sitä (Kleidermacher 1991, 70). Maailmalle Tapping-tekniikka tuli tunnetuksi Edward Van Halenin kautta Van Halen yhtyeen debyyttilevyllä vuonna 1978. Tony MacAlpine on tehnyt sovituksen Tapping-tekniikkaa käyttäen J.S.Bachin c-molli preludista, DWK 1. 
Kuva 5.

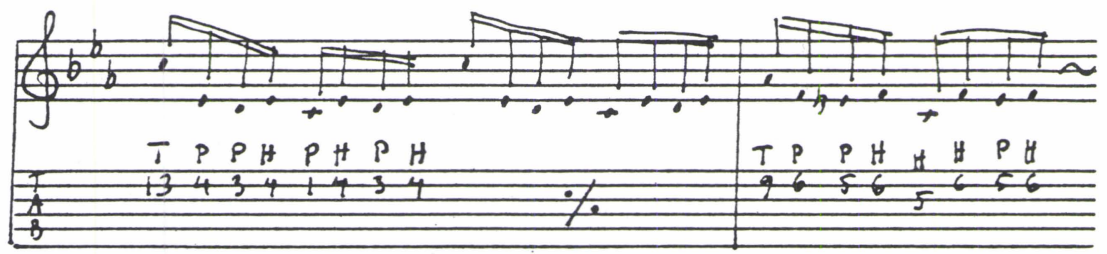

\section{String-Skipping}

String-Skipping -tekniikalla jo nimensäkin puolesta hypätään jonkun tai joidenkin kielten yli. Hyppyä voidaan käyttää kohdissa, joissa melodiankulun kannalta on järkevämpää jättää jokin kieli välistä pois, ennen kaikkea jos kyseessä on nopeasti soitettava sävelkulku. Esimerkiksi $e^{1}$-sävelestä nouseva vähennetty kuusisävelinen asteikko voidaan sormittaa vaikkapa seuraavanlaisesti:

Kuva 6.

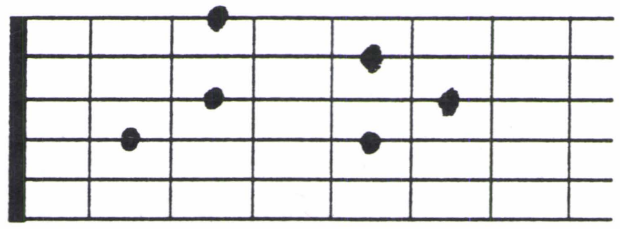

Vasemman käden sivuttaisliike on pieni ja sormien asemat pysyvät paikoillaan. Jokaista sormea vastaa oma nauhavälinsä otelaudalla. Nopeuden kasvaessa kyseinen sormitus muuttuu soittimellisesti epäsuotuisaksi. String-skipping -tekniikalla voidaan vähennetty sävelkulku sormittaa seuraavanlaisesti:

Kuva 7.

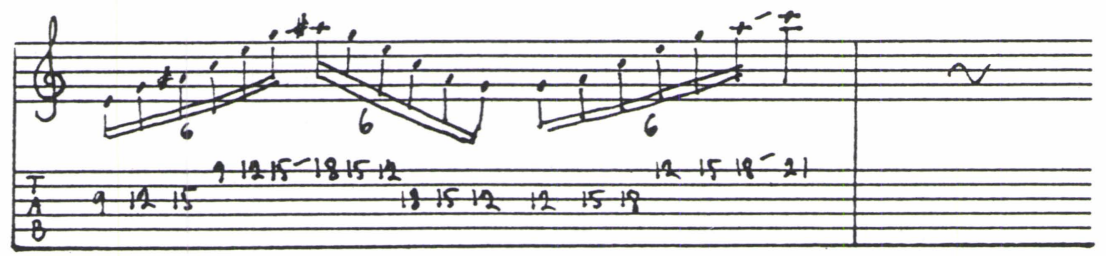


Toinen kieli jää välistä pois melodian jatkuessa luontevasti kolmannelta kieleltä ensimmäiselle kielelle. Asema ja sormitukset pysyvät täsmälleen samoina hypätessä yhden kielen ylitse. Tämän johdosta toiselle kielelle muodostuu eräänlainen symmetria-akseli, jonka molemmilla puolilla on täsmälleen toistensa kaltaiset kuviot.

String-Skipping -tekniikan huono puoli on sen aiheuttamissa fyysisissä vaatimuksissa. Jos soittajalla on pieni käsi, on erittäin vaikeaa soittaa kyseinen sävelkulku, varsinkin mitä alemmassa asemassa ollaan otelaudalla, koska nauhaväli kasvaa alaspäin mentäessä. Kappaleen esimerkissä on liu'ulla vaihdettu pientä terssiä ylempään asemaan, joka mahdollistaa melodiakulun sekvenssoinnin.

\section{Sweep-Picking}

Arpeggiot ovat olleet klassisessa musiikissa jo vuosisatoja, mutta sähkökitaran käyttöön ne ovat laajemmalti tulleet vasta muutama vuosi sitten. Jazz-musiikin parissa kitaristit ovat soittaneet jo pitempään pieniä arpeggioita, lähinnä muutamasta sävelestä koostuvia fraseerauksia. Arpeggioissa soitettavien sävelien määrä on kasvanut neoklassisuuden myötä. Arpeggion soittamista vastaa termi SweepPicking (pyyhkäisy). Ideana on soittaa plektralla halutut sävelet kielien yli yhteen suuntaan. Tällainen arpeggio voidaan soittaa joko niin, että dempataan voimakkaasti oikeankäden kämmenellä tai sävel sammutetaan välittömästi sormea nostamalla niin, ettei se kuitenkaan irtoa kielestä. Tärkeintä on kiinnittää erityistä huomiota artikulaatioon. Sävelet täytyy soittaa mahdollisimman erottelevasti. (Moore 1988, video).

Kuva 8.

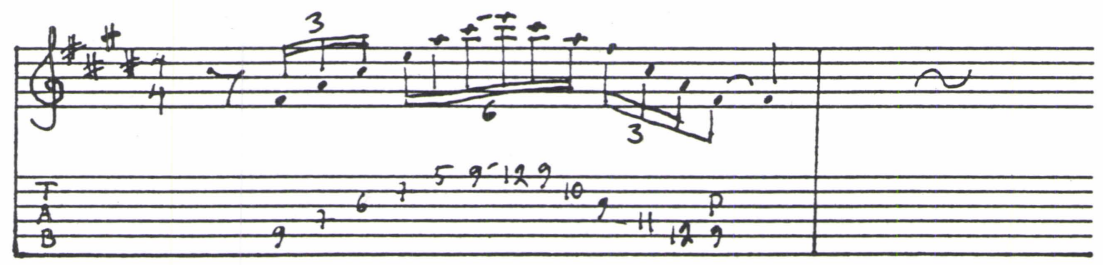


Tämän arpeggion oikein soittaminen edellyttää kahden eri aseman käyttöä: ylöspäin mentäessä al€mpaa ja alaspäin tultaessa ylempää asemaa. Arpeggion tullessa ensimmäiselle kielelle $a^{1}$-säveleen tehdään Hammer-On -lyönti vasemman käden neljännellä sormella, jolloin saadaan sävel cis $^{2}$. Tästä liu'uttamalla sormea päästään ylempään asemaan, josta voidaan tulla luontevasti alas, jolloin viimeinen sävel syntyy Pull-Off -päästöä käyttäen.

\section{Lopuksi}

Uusien tyylisuuntien ajankohdan määritteleminen on yleensä vaikeaa, koska kehitys etenee useimmiten melko hitaasti tulevaan suuntaan. Missä vaiheessa kulkee se raja, että uuden ja vanhan välillä on jo olennaisesti eroa, että ne pitäisi erottaa toisistaan. Historian varrelta voidaan huomata paljonkin asioita, jotka ovat johtaneet kyseisen tyylin syntymiseen. Näin myös neoklassismissa; ainakin osittain.

Harvinaista kuitenkin on, että jollekin tyylille voidaan määritellä tarkka alkamiskohta. Neoklassismi tekee kuitenkin tässä kohden poikkeuksen. Poikkeuksellinen neoklassismi on myöskin siinä suhteessa, että niin nopeasti kuin se tulikin, niin vähintään yhtä nopeasti se hävisikin.

Yngvie J. Malmsteen teki ainostaan yhden neoklassisuutta edustavan levyn. Toisella levyllä, "Marching Out", joka ilmestyi vuonna 1985 , oli mukana laulusolisti niin kuin jo ensimmäisen levyn kahdessa kappaleessa. Vaikka toisella levyllä on laulusolisti, se muistuttaa tyyliltään kuitenkin paljon ensimmäistä. Laulusolistin myötä on Yngvie J. Malmsteen suuntautunut enemmän kaupallisille markkinoille ja sitä myöden musiikki on muuttunut lähinnä iskelmäheavyksi. Uuden levyn, "Fire And Ice" vuodelta 1992, alkusoitoissa ja soolo-osissa on vielä selvästi tunnistettavissa Malsmteenin kitaransoittotyyli.

Paljon pitemmälle ei jaksanut Tony MacAlpinekaan. Hän teki kaksi soololevyä: ensimmäinen, "Edge Of Insanity", vuodelta 1986 ja toinen, "Maximum Security", vuodelta 1987. Kahden kokonaan instrumentaalisen levyn jälkeen hän perusti yhtyeen, MacAlpine, joka on tehnyt yhden levyn, "Eyes Of The World", vuonna 1990. Tällä levyllä on ainoastaan muutama lyhyt soolo, joten musiikin tyylin vaihdos on ollut melkoinen.

Vuoden 1990 maaliskuussa antamassaan haastattelussa Vinnie 134 
Moore kertoo uudesta projektistaan. Hän haluaa koota yhtyeen, jossa olisi laulaja solistina. Suunnitelmista ja laulusolisti Matt Bradleysta huolimatta mitään tällaista yhtyettä ei kuitenkaan tullut, vaan Moore julkaisi 1991 kolmannen soololevyn, "Meltdown", joka oli täysin instrumentaali. Instrumentaalisuudesta huolimatta levy ei kuitenkaan ole millään muotoa neoklassisuutta edustava äänite, vaan lähinnä suoraa heavyrockia ilman laulusolistia.

Vinnie Mooren neoklassinen tuotanto jäi kahteen levyyn, joista ensimmäinen, "Mind's Eye", ilmestyi vuonna 1987 ja toinen, "Time Odyssey", vuonna 1988.

Syitä neoklassismin äkkinäiseen lopahtamiseen on varmastikin monia. Päällimmäisenä lienee kuitenkin ollut kyseisen tyylin epäkaupallisuus, joka ei koskaan olisi saavuttanut suuren yleisön suosiota. Toisaalta uusien sävellyksellisten ideoiden löytäminen on saattanut olla vaikeaa ja näin ollen on haluttu välttyä itsensä toistamiselta muuttamalla kokonaan musiikkityyli toisenlaiseksi.

Vaikka neoklassisuuden vaikutus jäikin näennäisesti lyhytaikaiseksi, on se kuitenkin tuonut mukanaan paljon sellaista, jota ei ollut aikaisemmin. Yleensäkin harjoittelemisen käsite, joka ei ole välttämättä aina ollut sähkökitaran soitossa tärkeää, on tullut olennaiseksi osaksi nykypäivän rockkitaran soittoa.

Guitar Player ja Guitar World -lehdet julkaisevat paljon kitaristien haastatteluja, joissa käydään yksityiskohtaisesti kunkin soittajan tyyliä läpi nuottiesimerkein ja havainnollistavin kuvin. Lehdissä julkaistaan myös paljon transkriptioita kappaleiden kitarasooloista. Videoteollisuus on syytänyt markkinoille monen nimekkäänkin kitaristin opetusvideoita, joissa lehtien tapaan käsitellään soittoa elävän kuvan ja äänen avulla.

Neoklassisuus on ollut vain osa sitä kehitystä, joka tapahtunut Jimi Hendrixin ja Eric Claptonin jälkeen.

\section{Lähteet}

Lehtiartikkelit

Kleidermacher, Mordechai (1991), Where There's Smoke - There's Fire! Guitar World, February: 58-72. 
Klemm, Oliver (1988), The Guitar Hero Strikes Back. Metal Hammer, July:75.

Obrecht, Jas (1985), Rising Force. Guitar Player, May:59-71.

(1986), Tony MacAlpine. Dazzling Debut. Guitar Player, March:16,111.

(1987), Vinnie Moore's Stunning Debut. Guitar Player, June: 10.

Varney, Mike (1983), Spotlight. Guitar Player, February:142.

(1985), Spotlight. Guitar Player, January:96.

(1986a), Spotlight. Guitar Player, January:138.

(1986b), Spotlight. Guitar Player, August:128.

\section{Videot}

Moore, Vinnie (1988), Advanced Lead Guitar Technique. Hot Licks VGM 121.

(1989) Speed, Accuracy And Articulation. Hot Licks VGM 133.

\section{Äänitteet}

Deep Purple (1972), Machine Head. Warner Bros. BSK 3100.

MacAlpine, Tony (1986), Edge Of Insanity. Roadrunner Records RR 9760.

(1987), Maximum Security. Squawk 832 249-2.

Malmsteen, Yngvie J. (1984), Rising Force. Polydor 852 324-2.

(1985), Marching Out. Polydor 825 733-1.

(1992), Fire And Ice. Elektra 7559 61137-2.

Moore, Vinnie (1987), Mind's Eye. Shapnell SH 1027.

(1988), Time Odyssey. Squawk 834 634-2. 1991, Meltdown.

Relativity 88561 1067-2.

1 Syyskuun Guitar Player -lehdessä esitellään Tony MacAlpinen uutta levyä "Freedom To Fly", joka on täysin instrumentaali. Paluuta menneeseen MacAlpine puolustaa: "Unless it's a vocal project that involves some popular, colossar singer. I don't think the public wants to see me involved in a vocal band. Anyhow, I enjoy doing instrumental records". (Moses 1992, 16). 